\title{
Simulating Steam Oxidation of High Temperature Plant Under Laboratory Conditions: Practice and Interpretation of Data
}

\author{
Steve Osgerby*, Tony Fry* \\ National Physical Laboratory,United Kingdom \\ NPL Materials Centre,National Physical Laboratory \\ Teddington, Middlesex, TW11 OLW United Kingdom
}

Received: September 2, 2002; Revised: September 4, 2002

\begin{abstract}
Specimens of ferritic and martensitic steels have been exposed to steam atmospheres at $550{ }^{\circ} \mathrm{C}$ using three different experimental procedures. Slight differences in scale growth kinetics were observed but the major differences were in the morphology of the oxide scales that were formed. The microstructures of the scales have been compared with those formed on similar materials during service.
\end{abstract}

Keywords: ferritic steels, martensitic steels, steam oxidation, kinetics, microstructure

\section{Introduction}

During service components such as boiler, superheater and reheater tubes are exposed to steam at high pressure, flowing at high rates and often in the presence of heat flux. The precise conditions are difficult if not impossible to reproduce in the laboratory and some degree of simplification is necessary. Several exposure procedures are in common use in the laboratory - in ascending order of complexity these are:

- Water vapour in a carrier gas (usually argon);

- Flowing steam at atmospheric pressure;

- Static steam at high pressure;

- Flowing steam at high pressure.

None of these laboratory procedures include heat flux for which exposure in pilot plant is the main route available to assess its influence. Pilot plant exposure is normally the final stage in material selection.

A recent review ${ }^{1}$ has highlighted the scatter in data arising from the use of different exposure procedures. The purpose of the current work is to identify any differences in oxidation kinetics and scale microstructure arising from the exposure procedure that is used. The materials investigated were two low alloy ferritic steels (T22 and T23) and three batches of a 9 Cr1Mo martensitic steel.

*e-mail: steve.osgerby@npl.co.uk; tony.fry@npl.co.uk

Presented at the International Symposium on High Temperature Corrosion in Energy Related Systems, Angra dos Reis - RJ, September 2002.

\section{Experimental}

Material was supplied in the form of plate for the ferritic steels and tube for the $9 \mathrm{Cr} 1 \mathrm{Mo}$ martensitic steel. The composition (nominal for T22 and T23, actual for $9 \mathrm{Cr} 1 \mathrm{Mo}$ ) of each material is given in Table 1.

For the ferritic steels, specimens were machined in the form of rectangular blocks and the surface was prepared by abrasion using 600 grit $\mathrm{SiC}$ paper. The $9 \mathrm{Cr} 1 \mathrm{Mo}$ tube was cut into segments and the surface was left in the as-received condition. All the specimens were cleaned using industrial alcohol prior to exposure.

The specimens were exposed to steam at $550{ }^{\circ} \mathrm{C}$ for durations up to $1000 \mathrm{~h}$ using three procedures.

1. Gaseous argon and liquid water were passed into the furnace at rates of $100 \mathrm{ml} / \mathrm{min}$ and $0.0736 \mathrm{ml} / \mathrm{min}$ respectively. The water is gasified on entry to the furnace to give the desired argon $/ 50 \% \mathrm{H}_{2} \mathrm{O}$ by volume.

2. Water in a reservoir is boiled outside the furnace and the steam flows naturally through the furnace.

3. Steam is generated in a sealed pressure vessel. A nominal pressure of 50 bar was chosen for these tests; excess pressure is released through an outlet valve.

Control of water chemistry during exposure was limited to ensuring that the water was de-ionised and de-aer- 
Table 1. Alloy Composition.

\begin{tabular}{lcccccccccccccc}
\hline Alloy & & & \multicolumn{1}{c}{ Composition (wt.\%) } & & & & & & \\
& $\mathrm{C}$ & $\mathrm{Si}$ & $\mathrm{S}$ & $\mathrm{P}$ & $\mathrm{Mn}$ & $\mathrm{Cr}$ & $\mathrm{Mo}$ & $\mathrm{Co}$ & $\mathrm{V}$ & $\mathrm{N}$ & $\mathrm{Nb}$ & $\mathrm{W}$ & $\mathrm{B}(\mathrm{ppm})$ & $\mathrm{Al}$ \\
\hline T22 & 0.10 & 0.5 & 0.025 & 0.025 & 0.6 & 2.25 & 0.54 & & & & & & & \\
T23 & 0.07 & 0.5 & 0.01 & 0.03 & 0.35 & 2.25 & 0.17 & & 0.25 & 0.03 & 0.05 & 1.6 & 6 & 0.03 \\
9Cr1Mo(1) & 0.11 & 0.41 & 0.004 & 0.02 & 0.45 & 8.82 & 0.95 & 0.019 & & & & & & \\
9Cr1Mo(2) & 0.12 & 0.63 & 0.009 & 0.018 & 0.47 & 9.89 & 1.01 & 0.024 & & & & & \\
9Cr1Mo(3) & 0.10 & 0.59 & 0.007 & 0.006 & 0.50 & 9.70 & 1.00 & 0.031 & & & & & & \\
\hline
\end{tabular}

ated prior to conversion to steam. For the exposures under flowing steam and the argon $/ 50 \% \mathrm{H}_{2} \mathrm{O}$ mixture, water was taken from a de-ionised supply and distilled, de-aerated by bubbling nitrogen through the reservoir before final conversion to steam by boiling. In the autoclave the water was de-aerated during leak testing of the system under highpressure nitrogen prior to heating.

After exposure the specimens were plated with nickel to retain the oxide, sectioned and mechanically polished. Oxide scale thickness was measured at 24 positions, evenly spaced along the specimen surface, using a calibrated eyepiece graticule in the optical microscope. The resolution of these measurements is $1 \mu \mathrm{m}$.

\section{Results and Discussion}

In general the oxide scale formed in two layers - an outer layer of magnetite and an inner layer of iron-chromium spinel. In some cases internal oxidation was also observed. Some spallation of the outer oxide scale was observed for T23 but not in the other materials. This is believed to be largely a function of the higher creep strength of T23 compared to T22. Figure 1, which is taken from the work of Masuyama et al. ${ }^{2}$, shows that T23, referred to in Fig. 1 by its alternative nomenclature, HCM2S, has rupture lives $\sim 5$ times that of T22 for the same stress at $550{ }^{\circ} \mathrm{C}$. Stresses that are developed in the scale during cooling relax more slowly than in the weaker T22 material and hence spallation occurs in thinner scales when cooled to room temperature. This mechanism is described in more detail by Evans and Lobb $^{3}$.

Oxide scale thickness as a function of time and exposure procedure is shown in Fig. 2 for both material classes. Although there is scatter in the data some general observations can be made. The scales grown under flowing steam are thicker than those grown in static high-pressure steam in the autoclave. The scales grown under $\operatorname{argon} / 50 \% \mathrm{H}_{2} \mathrm{O}$ were intermediate in thickness between these extremes.

The $9 \mathrm{Cr}$ material exhibited lower growth rates than either of the $2 \frac{1}{4} 4 \mathrm{Cr}$ steels. This is an expected result and con-

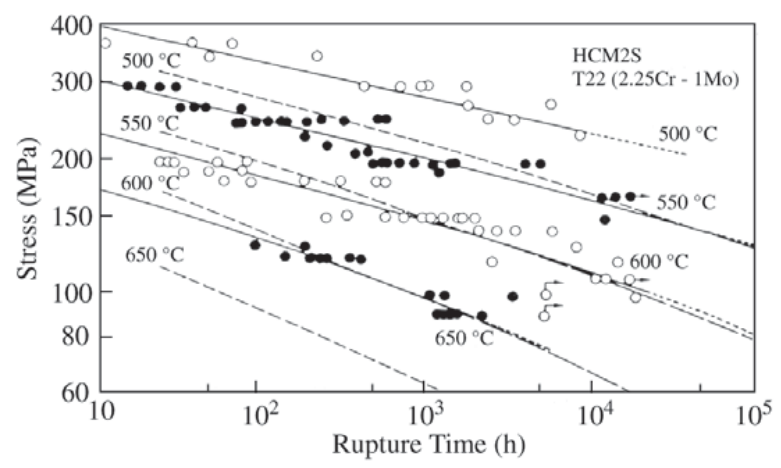

Figure 1. Creep Properties of T22 and T23 (after Ref. 2).

firms the well-known beneficial influence of $\mathrm{Cr}$ on steam oxidation resistance ${ }^{4}$. There were no significant differences in behaviour between T22 and T23 indicating that the presence of $\mathrm{Nb}$ and $\mathrm{W}$ in $\mathrm{T} 23$ had no influence on the steam oxidation properties.

The three 9Cr1Mo steels showed fairly consistent behaviour with the oxidation rate in $9 \mathrm{Cr} 1 \mathrm{Mo}(1)$ greater than that in $9 \mathrm{Cr} 1 \mathrm{Mo}(2)$ which in turn was greater than that in $9 \mathrm{Cr} 1 \mathrm{Mo}(3)$. This ranking is probably a result of the slightly lower $\mathrm{Cr}$ and $\mathrm{Si}$ content in $9 \mathrm{Cr} 1 \mathrm{Mo}(1)$ in comparison with the other two materials and the lower $\mathrm{C}$ content of $9 \mathrm{Cr} 1 \mathrm{Mo}(3)$ compared to $9 \mathrm{Cr} 1 \mathrm{Mo}(2)$. It is suggested that $\mathrm{C}$ affects the oxidation resistance through tying up $\mathrm{Cr}$ in the form of carbides: this $\mathrm{Cr}$ would otherwise be available for oxidation resistance.

Significant differences in the morphology of the oxide scales grown under different conditions can be observed. The behaviour of the $2^{1 / 4} \mathrm{Cr}$ steels is illustrated in Fig. 3 . Scales grown under $\mathrm{Ar} / 50 \% \mathrm{H}_{2} \mathrm{O}$ show a compact inner spinel layer with an outer porous magnetite layer. There are traces of haematite at the surface but these are very thin and discontinuous. The scale grown under flowing steam at room temperature has a compact outer layer of magnetite with an inner spinel layer that contains a plane of massive defects. 


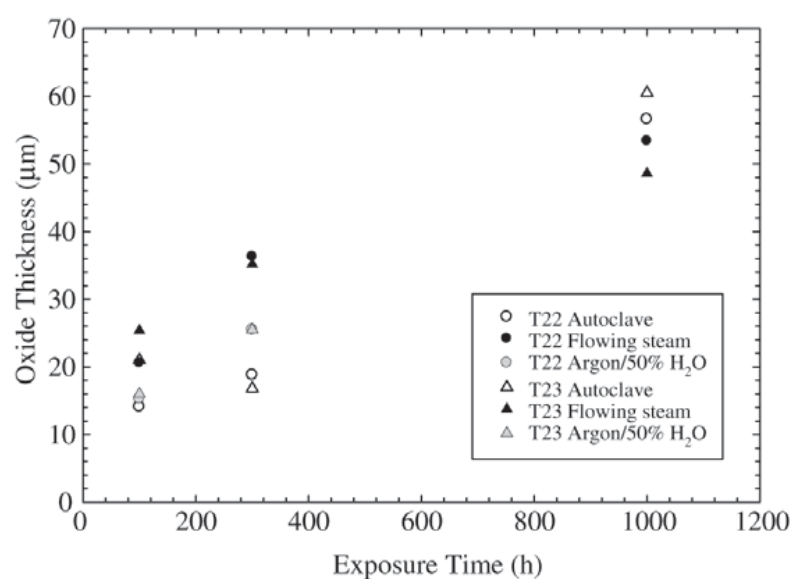

(a)

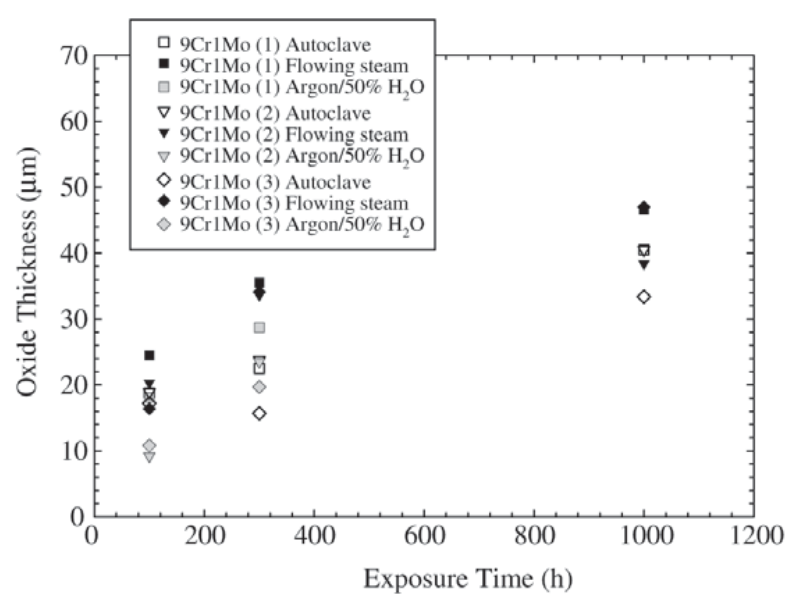

(b)

Figure 2. Scale growth kinetics for materials grown using different laboratory procedures: a) low alloy ferritic steels; b) $9 \mathrm{Cr} 1 \mathrm{Mo}$ martensitic steel.

In contrast the scale grown under high-pressure static steam is compact throughout although there is some evidence of roughening at the surface of the outer scale.

Similar diversity in the scales grown under different conditions is observed in the $9 \mathrm{Cr} 1 \mathrm{Mo}$ steels (Fig. 4). Two additional features in the scales grown on these materials are the presence of internal oxidation below the spinel under all conditions and the development of wavy scale/substrate interface and surface in the scales grown under flowing steam and static high pressure steam.

The growth mechanisms that cause this change in microstructure of the oxide scale between the different exposure techniques are not apparent: the differences in the activity

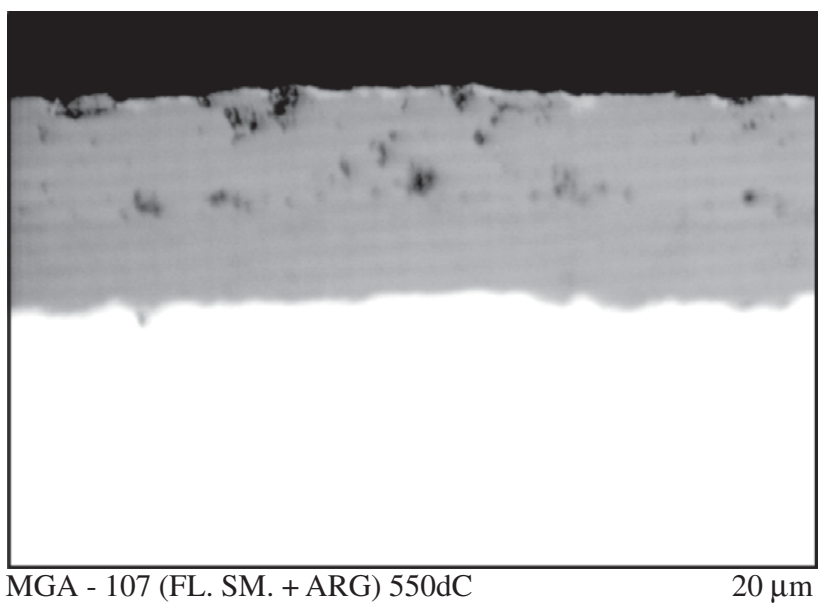

(a)

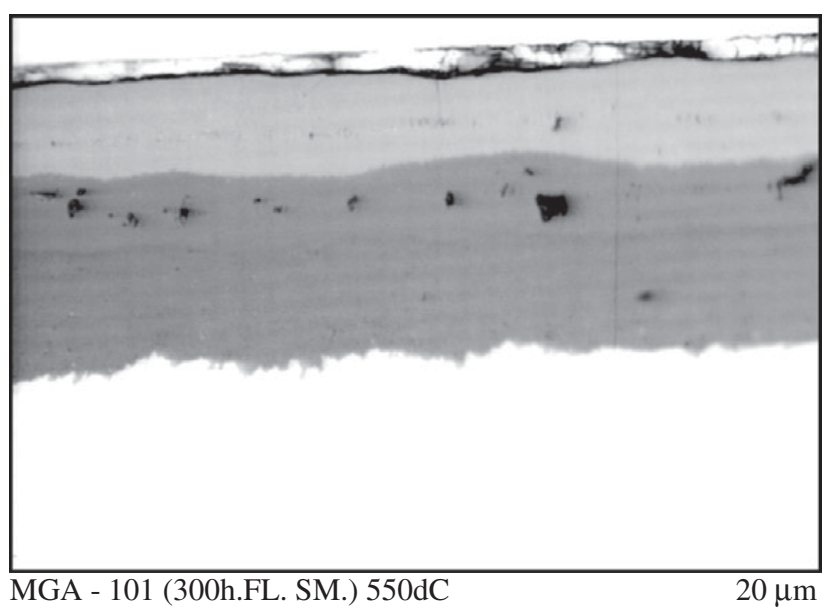

(b)

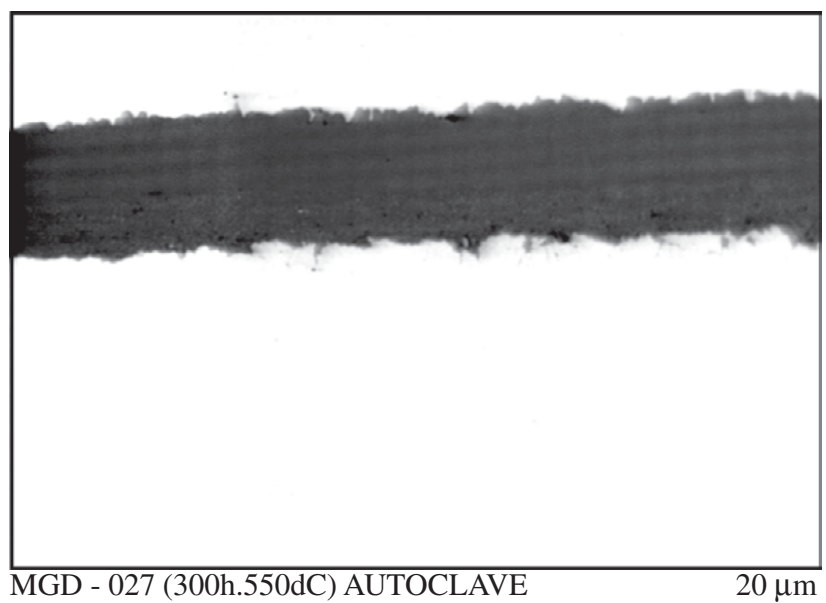

(c)

Figure 3. Microstructure of oxide scales grown on T22 ferritic steel at $550{ }^{\circ} \mathrm{C}$ for $300 \mathrm{~h}$ using different laboratory procedures: a) $\operatorname{argon} / 50 \% \mathrm{H}_{2} \mathrm{O} ;$ b) flowing steam; c) static high pressure steam. 


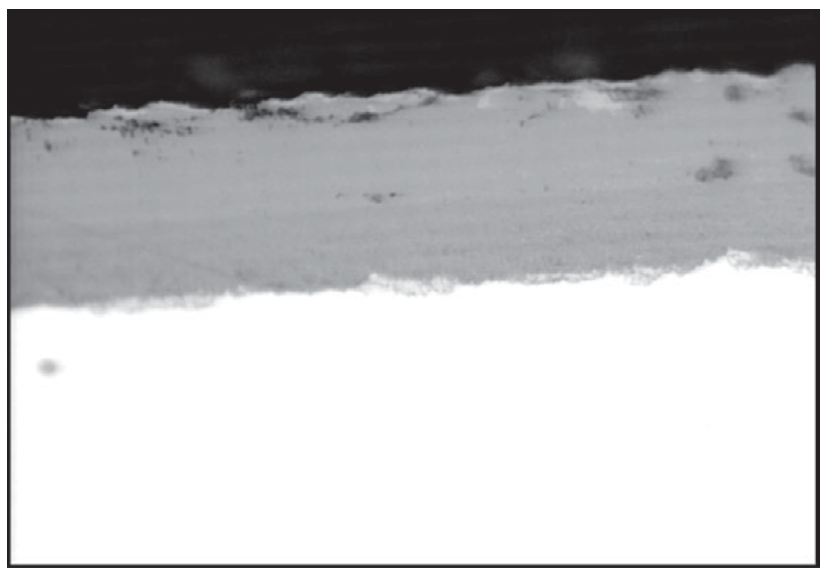

MGD - 103B (FL SM. + ARG 550d 300h.

(a)

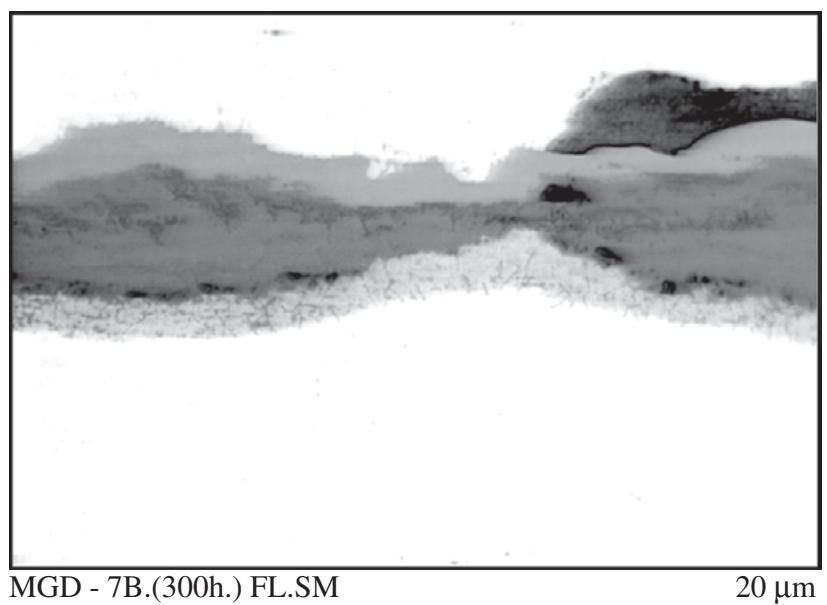

(b)

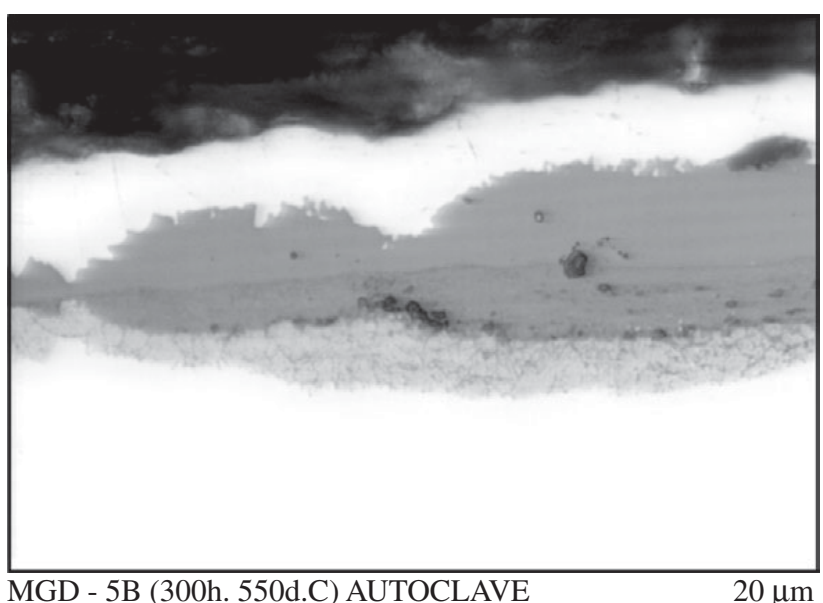

(c)

Figure 4. Microstructure of oxide scales grown on $9 \mathrm{Cr} 1 \mathrm{Mo}(2)$ steel at $550{ }^{\circ} \mathrm{C}$ for $300 \mathrm{~h}$ using different laboratory procedures: a) argon $/ 50 \% \mathrm{H}_{2} \mathrm{O}$; b) flowing steam; c) static high pressure steam. of the active species in the various atmospheres are minor. One possibility is that the different experimental facilities produce a range of local flow rates that may affect the scale formation.

The development of a wavy interface is illustrated in Fig. 5 for the $9 \mathrm{Cr} 1 \mathrm{Mo}(2)$ material. Here, individual scale thickness measurements are represented on a probability plot. A horizontal line indicates a uniform scale whilst increasing slope to the data indicates increasing variation in the scale thickness. Two effects are apparent. Firstly the wavy interface develops with time - data from the $100 \mathrm{~h}$ exposures (open symbols) follow an almost horizontal path; the slope of the data generally increases with increasing exposure time (black- and gray-filled symbols). Secondly the data from scales grown under argon $/ 50 \% \mathrm{H}_{2} \mathrm{O}$ are much more homogeneous in thickness than those grown under flowing steam or in the autoclave.

Specimens were cut from pipes that had been exposed to steam during service. The piece of T22 had been in service for $19000 \mathrm{~h}$ at $550{ }^{\circ} \mathrm{C}$ and the $9 \mathrm{Cr} 1 \mathrm{Mo}$ material had been at $590{ }^{\circ} \mathrm{C}$ for $28000 \mathrm{~h}$. The steam pressure during service was unknown. Cross sections of these materials were prepared and examined in the optical microscope. The structure of the oxides is shown in Fig. 6. The scales are significantly thicker that those formed in the laboratory, due to the much longer exposure time, and do not appear to have spalled. In both cases the outer magnetite layer shows some porosity whilst the inner spinel has a fully dense structure. Rather surprisingly it is the structure of the scales formed

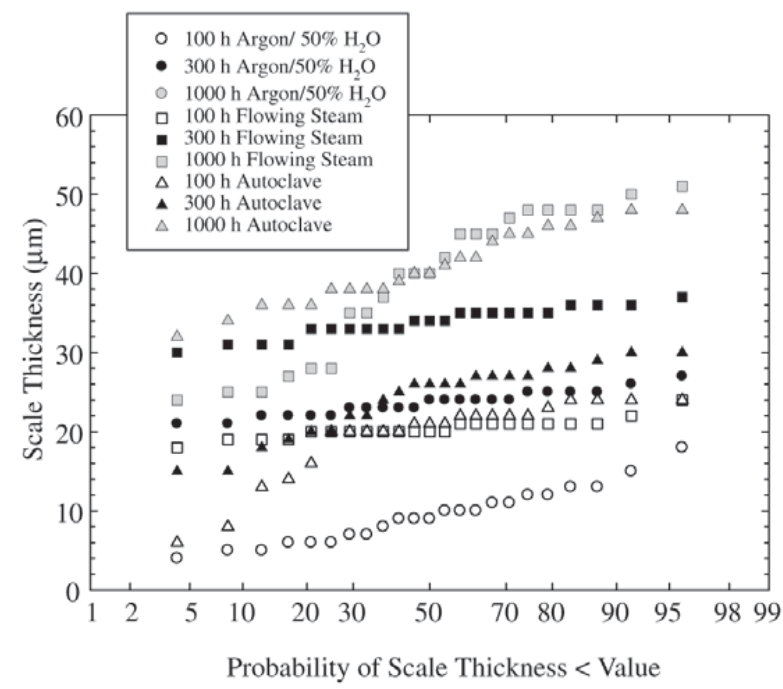

Figure 5. Probability plot of oxide scale thickness for $9 \mathrm{Cr} 1 \mathrm{Mo}(2)$ material, exposed to steam at $550{ }^{\circ} \mathrm{C}$ using various procedures. 


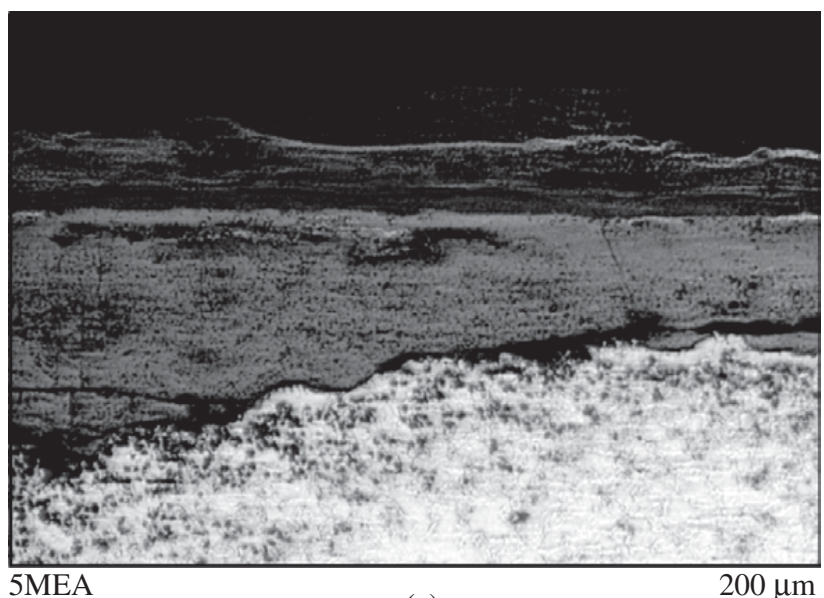

(a)

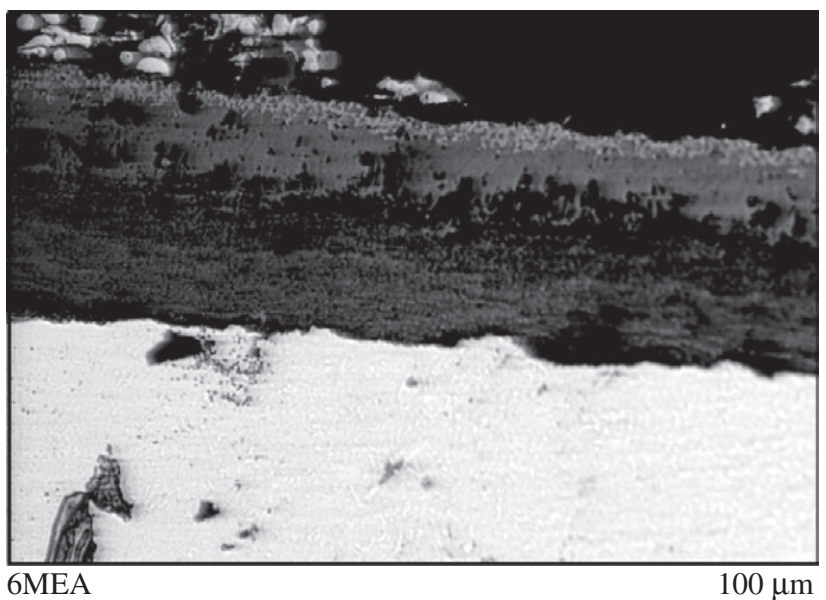

(b)

Figure 6. Morphology of oxide scales formed in service in a steam environment: a) T22 after $19000 \mathrm{~h}$ at $550{ }^{\circ} \mathrm{C}$; b) $9 \mathrm{Cr} 1 \mathrm{Mo}$ after $28000 \mathrm{~h}$ at $590{ }^{\circ} \mathrm{C}$.

under the argon $/ 50 \% \mathrm{H}_{2} \mathrm{O}$ mixture that is most similar to that which is formed in service. This procedure is the most dissimilar to the actual service conditions so it would be expected to produce the least representative scales.

Future work will attempt to determine the different oxidation mechanisms that operate in each laboratory procedure and to explain how the different scale morphologies are produced.

\section{Conclusions}

Specimens of ferritic and martensitic steels have been exposed to steam environments at $550{ }^{\circ} \mathrm{C}$ using three different laboratory procedures. Although the scale thicknesses measured after a given time were similar for all the procedures, there were significant differences in the microstructure of the scales that were grown under the various conditions.

Examination of material that had been retired from service, showed that using an argon $/ 50 \% \mathrm{H}_{2} \mathrm{O}$ mixture produced the scale most similar in morphology to that grown in service.

\section{Acknowledgements}

This work was carried out under the Life Performance of Materials Programme, a programme of underpinning research funded by the United Kingdom Department of Trade and Industry.

The authors wish to express their thanks to British Energy who supplied the three batches of $9 \mathrm{Cr} 1 \mathrm{Mo}$ material and to Powergen who supplied the service exposed tubes.

\section{References}

1. Fry, A.; Osgerby, S.; Wright, M. Oxidation of Alloys in Steam Environments, A Review, NPL Report MATC (A)90, National Physical Laboratory, UK, July 2002.

2. Masuyama, F.; Yokoyama, T.; Sawaragi, Y.; Yokoyama, T. Materials for Advanced Power Engineering, Eds D Coutsouradis et al., Kluwer Academic Publishers, p. 173-181, 1994.

3. Evans, H.E.; Lobb, R.C. Corros. Sci., v. 24, n. 209, 1984.

4. Manning, M.I.; Metcalfe, E. Oxidation of Ferritic Steels in Steam, in Proc Conf Ferritic Steels for Fast Reactor Steam Generators", BNES, London, p. 378-382, 1978. 